\title{
Emerging Role of CAR T Cells in Non-Hodgkin's Lymphoma
}

\author{
Mauro P. Avanzi, MD, PhD, and Renier J. Brentjens, MD, PhD ${ }^{\mathrm{a}, \mathrm{b}}$
}

\begin{abstract}
Adoptive T-cell therapy with chimeric antigen receptor T cells (CAR-Ts) has produced impressive clinical responses among patients with B-cell malignancies, and several groups have published positive results using anti-CD19 CAR-Ts for the treatment of B-cell acute lymphoblastic leukemia. Recently, new data from clinical trials have demonstrated the benefits of CAR-T therapy in the non-Hodgkin's lymphoma (NHL) setting. This review describes some of the most recent and promising advances in engineered T-cell therapy, with particular emphasis on the clinical benefits of NHL treatment.
\end{abstract}

J Natl Compr Canc Netw 2017;15(11):1429-1437 doi: 10.6004/jnccn.2017.7045

Adoptive T-cell therapy with chimeric antigen receptor T cells (CAR-Ts) has emerged as an effective therapy for the treatment of malignancies, and several groups have published results using anti-CD19 CAR-Ts mostly for the treatment of B-cell acute lymphoblastic leukemia (B-ALL) and non-Hodgkin's lymphoma (NHL). ${ }^{1-4} \mathrm{Al}$ though clinical experience with CAR-Ts is more abundant in ALL, the benefits are being observed in other hematologic malignancies, such as NHL, chronic lymphocytic leukemia (CLL), and multiple myeloma (MM). Lymphomas are a heterogeneous group of cancers that arise from developing lymphocytes; according to the $\mathrm{WHO}$, there are $>35$ distinct entities. ${ }^{5}$ Lymphomas have been separated into NHL and Hodgkin lymphoma (HL); NHL includes a wide group of lymphoid malignancies that derive from $\mathrm{B}$, T, or natural killer (NK) cells. ${ }^{6} \mathrm{Al}$ though malignant cells acquire genetic abnormalities, they also preserve many features of the cells from which they originated, meaning that target antigens that could potentially be used in any immunotherapy treatment are usually expressed on both lymphoma cells and their

From ${ }^{a}$ Department of Medicine, Memorial Sloan Kettering Cancer Center, and 'Weill Cornell Medicine, New York, New York.

Submitted August 17, 2017; accepted for publication October 2, 2017.

Dr. Brentjens has disclosed that he is a co-founder, stockholder, and

consultant for Juno Therapeutics Inc. Dr. Avanzi has disclosed that he has nonmalignant counterparts. HL also differs from NHL in that the malignant Reed-Sternberg (RS) cells are relatively rare, and that nonmalignant cells that infiltrate the microenvironment play a key role in the biology of HL.? It has become increasingly evident that elements of the tumor microenvironment, far from being inactive or part of an antitumor inflammatory response, actually enable cancer pathogenesis and progression. In general, B-cell NHL (B-NHL) and HL are highly sensitive to both chemotherapy and radiotherapy and, despite the presence of disseminated disease at diagnosis in most cases, remain eminently curable. However, relapse and resistance prevent the ultimate goal of achieving cure in all patients. ${ }^{8}$

In the past few decades, the introduction of improved chemotherapy regimens, monoclonal antibodies (mAbs), radioimmunotherapy, and targeted adoptive T-cell therapies have provided significant advances in management. ${ }^{8}$ Lymphomas are highly susceptible to cellular therapies, including stem cell transplant ${ }^{9}$ and adoptive transfer of Epstein-Barr virus (EBV)-specific T cells, which could be considered the precursor to CAR-

no financial interests, arrangements, affiliations, or commercial interests with the manufacturers of any products discussed in this article or their competitors.

Correspondence: Renier J. Brentjens, MD, PhD, Memorial Sloan Kettering Cancer Center, 1275 York Avenue, Mailbox 242, New York, NY 10065.

E-mail: brentjer@mskcc.org 
T therapy. ${ }^{10}$ Recently, adoptive T-cell therapies with CAR-Ts have demonstrated wide application and significant results for the treatment of B-cell malignancies. CAR-Ts consist of an engineered extracellular domain from a single-chain variable fragment $(\mathrm{scFv})$, composed of the antigen-binding regions of both heavy and light chains of mAbs, a transmembrane domain, an intracellular costimulatory domain (more commonly CD28 or 4-1BB), and a CD3६.11,12 Unlike conventional T cells, CAR-Ts recognize unprocessed antigen, and therefore eradicate tumor cells independently of their expression of major histocompatibility complex (MHC) antigens. This circumvents some of the major mechanisms through which tumors avoid MHC-restricted T-cell recognition, such as the downregulation of human leukocyte antigen (HLA) class I molecules and defective antigen processing. ${ }^{12,13}$ Contrary to B-cell lymphomas, peripheral T-cell lymphomas encompass a heterogeneous group of diseases that have generally been associated with poor prognosis. ${ }^{5}$ Currently, T-cell lymphomas present a much more challenging treatment landscape and, due to limitations regarding antigen availability, there are very few adoptive T-cell therapies targeted against a T-cell lymphoma antigen. ${ }^{14,15}$

\section{Antigen Selection}

The consistent expression of the B-cell lineage markers CD19, CD20, and CD22 across most B-cell malignancies, ${ }^{16,17}$ and the safety and efficacy of anti-CD19/ CD20/CD22 mAbs previously described in these diseases, made them the ideal targets for CAR-Ts. ${ }^{18-21}$ However, normal B cells also express most lymphoma target antigens suitable for CAR recognition, leading to B-cell elimination, a relatively benign disorder that can be treated with the use of intravenous immunoglobulin. Antigens more specific and restricted for B-cell malignancies could also be used as a target, and therefore display fewer side effects compared with conventional anti-CD19/CD20/CD22 CAR-Ts. Among these alternative antigens is BCMA (B-cell maturation antigen), which is predominantly expressed by plasma cells, subsets of mature B cells, and the $\kappa$ or $\lambda$ light chain of malignant $B$ cells. In the $T$ cell lymphoma setting, however, finding an ideal antigen to target is more challenging due to the shared expression of many targetable antigens between normal and malignant $\mathrm{T}$ cells. ${ }^{22}$ This shared expression of antigens can cause fratricide in CAR-Ts, inhibiting their proliferation and viability, and in the clinic may result in eradication of normal peripheral $\mathrm{T}$ cells. ${ }^{22}$ Such an on-target/off-tumor effect could lead to more severe and life-threatening side effects and be less clinically manageable than the depletion of normal B cells found within the CD19, CD20, or CD22 targeted therapies. ${ }^{4} \mathrm{HL}$ tumor cells have a very low expression of CD19 antigen and therefore are not eligible for anti-CD19 therapy with CAR-Ts. ${ }^{23}$ However, despite the lack of CD19 expression, almost all Hodgkin and RS (HRS) cells overexpress the CD123 and CD30 surface molecules, which could be potentially used as a target for adoptive T-cell therapy. ${ }^{24}$

\section{CAR-Ts Against NHL}

The CD19 antigen is expressed during all stages of B-cell differentiation and is still present in most Bcell lymphomas. ${ }^{16}$ Therefore, most of the clinical trials conducted with CAR-Ts in the B-cell lymphoma setting will target CD19. Different scFvs can be used to target the CD19 antigen on the cell surface, and those more commonly used in clinical trials are FMC63 or SJ25c. ${ }^{25}$ Initial clinical trials for the treatment of lymphoma were conducted at the City of Hope Medical Center and used a CD19-targeted first-generation CAR-T (FMC63 19z CAR-T), without any costimulatory signaling. ${ }^{26}$ Patients with relapsed/refractory (R/R) follicular lymphoma (FL) were treated with anti-CD19 first-generation CAR-Ts after lymphodepletion with fludarabine and subcutaneous interleukin-2 (IL-2) was administered concomitantly to T-cell therapy. Despite demonstrating the feasibility and safety of this new approach, anti-CD19 adoptive T-cell therapy with first-generation CAR-Ts failed to demonstrate objective antitumor effects. ${ }^{26}$

Second-generation anti-CD19 CAR-Ts incorporate a costimulatory domain (CD28, 4-1BB, ICOS) and have demonstrated an enhanced antitumor effect in preclinical studies both in vitro and in vivo. ${ }^{27}$ Recently, clinical trials using second-generation CD19-targeted CAR-Ts with either CD28 or 4-1BB costimulatory domains have demonstrated significant results in the B-cell lymphoma setting, more specifically for the treatment of diffuse large B-cell lymphoma (DLBCL), primary mediastinal B-cell lymphoma (PMBCL), FL, splenic marginal zone lymphoma (SMZL), and mantle cell lymphoma (MCL). 
The first patient with NHL was treated on a phase I trial at the NCI with a second-generation CD19. targeted CAR-T (FMC63 1928z). ${ }^{28}$ The patient presented with advanced R/R FL and received a lymphocyte-depleting regimen consisting of $60 \mathrm{mg} / \mathrm{kg}$ cyclophosphamide daily for 2 days followed by 5 daily doses of $25 \mathrm{mg} / \mathrm{m}^{2}$ fludarabine. The day after the last fludarabine dose, the patient received $1 \times 10^{8}$ antiCD19 CAR-Ts intravenously, followed by $3 \times 10^{8}$ anti-CD19 CAR-Ts the next day. After the second CAR-T infusion, the patient received $720,000 \mathrm{IU} / \mathrm{kg}$ IL-2 intravenously every 8 hours, for a total of 8 doses. The patient achieved partial response (PR) for 32 weeks after anti-CD19 CAR-T therapy. ${ }^{28}$

A follow-up trial from the NCI group was conducted in patients with FL or SMZL. ${ }^{29}$ In this trial, patients were preconditioned with cyclophosphamide, $60 \mathrm{mg} / \mathrm{kg}$ for 2 days and fludarabine, $25 \mathrm{mg} / \mathrm{m}^{2}$ for 5 days and treated on day 0 with a single infusion of CAR-transduced T cells. IL-2 was also administered intravenously 3 hours after the CAR-T infusion at a dose of 720,000 IU/kg every 8 hours; doses of CAR-Ts ranged from $0.3 \times 10^{7}$ to $3.0 \times 10^{7}$ CAR-Ts $/ \mathrm{kg}$ bodyweight. Results from this trial showed that 3 of 4 patients with FL achieved PR, with a follow-up between 8 and 17 months, and 1 of 1 patient with MZL achieved PR, with a follow-up of 12 months. ${ }^{29}$

Another clinical trial from the NCI group used CD19-targeted CAR-T for the treatment of $\mathrm{R} / \mathrm{R}$ DLBCL or indolent B-cell lymphomas (SMZL and PMBCL). ${ }^{30}$ The preconditioning chemotherapy consisted of cyclophosphamide at a total dose of either 120 or $60 \mathrm{mg} / \mathrm{kg}$, followed by 5 daily doses of fludarabine, $25 \mathrm{mg} / \mathrm{m}^{2}$, and the dose of CAR-Ts used was $1 \times 10^{6}$ cells $/ \mathrm{kg}$. Exogenous IL-2 was not administered in this study. Of the 7 evaluable patients with DLBCL, 4 achieved complete response (CR), 2 obtained $\mathrm{PR}$, and 1 had stable disease (SD) after infusion of CAR-Ts. All 6 patients with indolent B-cell malignancies obtained either a PR or CR. Interestingly, this study also demonstrated that CAR-Ts were actually capable of infiltrating malignant lymph nodes and eradicating tumor cells. Anti-CD19 CAR-T gene detection with qPCR collected at multiple time points after CAR-T infusion determined that this level of CAR-positive blood cells varied considerably among patients and peaked between 7 and 17 days after infusion. In addition, CAR-T phenotype analysis demonstrated a decrease in the percentage of CAR-Ts with a central memory phenotype and an increase in the percentage of CAR-Ts with either an effector memory phenotype or a CD8+ effector memory phenotype and with PD-1 expression. ${ }^{30}$

A follow-up study from the NCI group in the DLBCL setting demonstrated that anti-CD19 CAR-Ts were capable of inducing $\mathrm{CR}$ in a high percentage of patients. ${ }^{31}$ Of the 7 evaluable patients, 5 achieved CR, 4 of whom had long-term durability with CR durations of 56, 51, 44, and 38 months, none of whom have experienced relapse at time of publication. Importantly, CR continued after recovery of nonmalignant polyclonal $\mathrm{B}$ cells in 3 of the 4 patients. ${ }^{31}$

Another trial from Baylor College of Medicine treated patients with R/R DLBCL and analyzed the safety and efficacy of both second- (1928z) and thirdgeneration (1928BBz) CAR-Ts. ${ }^{32}$ Patients were preconditioned with cyclophosphamide $\left(500 \mathrm{mg} / \mathrm{m}^{2} / \mathrm{d}\right)$ and fludarabine $\left(30 \mathrm{mg} / \mathrm{m}^{2} / \mathrm{d}\right)$ for 3 days and were simultaneously infused with 1 to $20 \times 10^{6}$ of both second- and third-generation CAR-Ts $/ \mathrm{m}^{2} 48$ to 72 hours after lymphodepletion. Of the 5 patients evaluable for response, 2 experienced $C R, 1$ had continued CR after autologous stem cell transplantation, 1 had a PR, and 1 had disease progression. ${ }^{32}$ Collectively, all of these phase I clinical trials demonstrated the feasibility and safety of this therapy and its efficacy against NHL.

Reports from a Fred Hutchinson Cancer Research Center (FHCRC) study used a defined T-cell subset administration of 1:1 CD4+/CD8+ ratio of CAR-Ts for the treatment of NHL. ${ }^{33}$ The 32 patients who proceeded to lymphodepletion chemotherapy and CD19 CAR-T infusion had previously received a median of 5 treatment regimens for de novo large B-cell lymphoma (LBCL; $n=11)$, LBCL that had transformed from indolent disease $(n=11)$, MCL $(n=4)$, or FL $(n=6)$; 16 patients had experienced relapse after autologous $(n=14)$ or allogeneic $(n=4)$ hematopoietic stem cell transplantation (HSCT). ${ }^{33}$ Lymphodepletion with cyclophosphamide, cyclophosphamide/etoposide, or cyclophosphamide/fludarabine was administered before CAR-T infusion. Between 36 and 96 hours after completion of chemotherapy, CAR-Ts were infused at 1 of 3 cell dose levels $\left(2 \times 10^{5}, 2 \times 10^{6}\right.$, or $\left.2 \times 10^{7} \mathrm{CAR}-\mathrm{Ts} / \mathrm{kg}\right)$. Results obtained after therapy demonstrated that CD19-targeted CAR-Ts were capable of inducing CR in 2 of 11 patients (18\%) with de novo aggressive B-cell lymphoma, 6 of 10 patients $(60 \%)$ with transformed LBCL, 2 of 5 patients (40\%) with FL, and 
0 of 4 patients $(0 \%)$ with MCL. ${ }^{33}$ Interestingly, this study demonstrated that consistent with the increase in CAR-T expansion and persistence observed with cyclophosphamide/fludarabine lymphodepletion, the addition of fludarabine to the lymphodepletion regimen was associated with improvement in the depth of response. Intensification of lymphodepletion through addition of fludarabine to cyclophosphamide, as in our study, increased the peak of expansion and long-term persistence of infused CAR-Ts and improved the CR rate, overall survival, and progression-free survival. ${ }^{33}$ An additional first-in-human trial was reported by the NCI group for the treatment of NHL using a fully human CAR-T as a means to avoid immunogenicity against the murine $\mathrm{scFv}$ of the chimeric receptor, and therefore enhance CAR-T expansion and persistence. ${ }^{34}$ This novel humanized CD19-targeted CAR$\mathrm{T}$ used a CD28 costimulatory domain and achieved an $86 \%$ response rate $(n=9) .{ }^{34}$

A study from University of Pennsylvania treated patients with double-hit NHL using (FMC63) 19BBz CAR-Ts. ${ }^{35}$ Double-hit DLBCL (DHL) is defined by chromosomal breakpoints affecting the MYC/8q24 locus and BCL2/18q21 and/or BCL6/3q27 loci and arise either from transformation of FL ( $\mathrm{tFL}$ ) or de novo and have no standard effective therapy in the relapsed setting. This study treated $R / R$ germinal center (GC) or nongerminal center (NGC) DLBCL, DHL, and tFL; 13 patients with DLBCL were enrolled and evaluable for response (7 GC, 5 NGC, 1 undetermined). Lymphodepleting chemotherapy regimens were bendamustine $\left(90 \mathrm{mg} / \mathrm{m}^{2} \mathrm{x}\right.$ $2 ; \mathrm{n}=1)$; cyclophosphamide $\left(1 \mathrm{~g} / \mathrm{m}^{2} ; \mathrm{n}=2\right)$; radiation and cyclophosphamide $\left(4,000 \mathrm{cGy}\right.$ and $750 \mathrm{mg} / \mathrm{m}^{2}$; $\mathrm{n}=1)$; modified EPOCH $(\mathrm{n}=3)$; and hyperfractionated cyclophosphamide $\left(300 \mathrm{mg} / \mathrm{m}^{2}\right.$ every 12 hours $\mathrm{x} 6 ; \mathrm{n}=6)$. A total of 12 patients received 5.00E+08 (range, 5.10-6.75E+06 cells $/ \mathrm{kg}$ ) CAR-Ts; 1 patient received $1.93 \mathrm{E}+08(3.10 \mathrm{E}+06$ cells $/ \mathrm{kg})$. At 3 months post-CAR T-cell therapy, overall response rate (ORR) was $52 \%$ for all patients (7/13); ORR at 3 months was $71 \%(5 / 7)$ for GC and 40\% (2/5) for NGC. The CR rate at 3 months was $38 \%(5 / 13)$; $43 \%$ (3/7) for GC; and 40\% (2/5) for NGC. Best response for all patients is CR in 6 of $13(46 \%) ; 57 \%$ (4/7) for GC; and 40\% (2/5) for NGC. Of 7 patients with GC DLBCL, 3 had tFL and all 3 achieved a CR; 2 of 7 patients with GC DLBCL had DHL, and both achieved a CR. At the time of study publica- tion, no patient who achieved a CR had experienced relapse. $^{35}$

Multicenter clinical trials recently demonstrated and confirmed the efficacy of anti-CD19 CAR-Ts against R/R NHL. The first trial (ZUMA-1) used the (FMC63) 1928z CAR-T and treated 101 patients with DLBCL, tFL, or PMBCL ${ }^{36}$ using one single infusion of $2 \times 10^{6} \mathrm{CAR}-\mathrm{Ts} / \mathrm{kg}$. The ORR was $82 \%$ (CR, $54 \%$ ), and at 8.7 months median follow-up, $44 \%$ remained in response and $39 \%$ in CR. ${ }^{36}$ Another phase II multicenter clinical trial (JULIET) used a (FMC63) 19BBz CAR-T for the treatment of DLBCL. ${ }^{37}$ This global, pivotal study showed a 3-month ORR of $45 \%$ (23 of 51 patients), with $37 \%$ achieving a CR and $8 \%$ achieving a PR. ${ }^{37}$ Another multicenter trial used the (FMC63) 19BBz CAR-T for the treatment of 14 patients with either DLBCL $(n=13)$ or MCL $(n=1)$. Two deaths were seen in the DLBCL arm due to disease progression. Results demonstrated an ORR of $82 \%(9 / 11)$ and a CR rate of $73 \%(8 / 11)$ for DLBCL and a CR rate of $\% \%(0 / 1)$ for MCL. ${ }^{38}$

The results obtained from the phase I and II clinical trials in NHL are significantly better than those seen in the benchmark historical SCHOLAR-1 trial, with ORR and CR rates of $26 \%$ and $7 \%$, respectively, obtained with standard therapies. ${ }^{39}$

\section{Other Targets Against NHL}

The disappearance of CD19 from the surface of malignant lymphocytes, or mutations in this target antigen, is a well-documented escape phenomenon in patients refractory to CD19-targeted CAR-T therapy. ${ }^{3,40}$ Despite the frequent expression of CD19 in B-cell malignancies, it may be downregulated or mutated in tumor cells, allowing these cells to become resistant to CD19-directed therapy. ${ }^{40,41}$ According to recent estimates, epitope loss accounts for up to $40 \%$ of reported relapses. ${ }^{3,40,42,43}$ Alternative markers, such as CD20 and CD22, are also frequently expressed in B-NHL and B-ALL, and therefore could potentially be used as a target for adoptive T-cell therapies. ${ }^{44,45}$ A CAR-T that targets CD20 and uses CD137 (4$1 \mathrm{BB}$ ) as a costimulatory domain (CAR.20-137z) was used in the clinical setting for the treatment of NHL in a Chinese PLA General Hospital trial, ${ }^{46}$ which enrolled 7 patients with R/R DLBCL and preconditioned them with distinctive combinations of multiple different chemotherapy regimens (eto- 
poside, vincristine, dexamethasone, cyclophosphamide, carboplatin, and high-dose cytosine arabinoside). Results showed that 1 of the 2 patients with no bulky tumor achieved a 14-month durable and ongoing CR by cell infusion only, and the other attained a 6-month tumor regression; 4 of 5 patients with bulky tumor burden were evaluable for clinical efficacy, in 3 of whom a 3- to 6-month tumor regression was observed. ${ }^{46}$ In a follow-up early-phase IIa clinical trial of anti-CD20 CAR-Ts ${ }^{47}$ that included 8 patients with DLBCL, 1 with MCL, 1 with FL, and 1 with PCMZL, 7 patients received cytoreductive chemotherapy, including cyclophosphamide for debulking and lymphocyte depletion, before the infusion, whereas the other 4 were not treated due to a smaller tumor burden and lower level of lymphocytes. The ORR was $81.8 \%$, with $54.5 \%$ of the patients $(6 / 11)$ achieving a CR and $27.3 \%$ (3/11) achieving a PR; the other 2 patients had SD. ${ }^{47}$

A third-generation anti-CD20-specific CAR$\mathrm{T}$ with both CD28 and 4-1BB domains was used in an FHCRC phase I trial for the treatment of indolent B-cell lymphomas and MCLs; 4 patients were enrolled, and 3 received T-cell infusions after cyclophosphamide lymphodepletion. ${ }^{48}$ Treatment was well tolerated, although 1 patient developed transient infusional symptoms; 2 patients without evaluable disease remained progression-free for 12 and 24 months, respectively, and the third patient had an objective PR and experienced relapse at 12 months after CAR-T therapy. ${ }^{48}$

A study from Baylor College of Medicine used CAR-Ts that target the $\kappa$ light chain ( $\kappa . C A R$ ) with the intention to treat a broad range of B-cell tumors (CLL, NHL, and MM) and to spare CD19+ endogenous B cells from CD19-targeted CAR-Ts. ${ }^{49}$ Patients on chemotherapy at the time of treatment could receive $\kappa . C A R$ no sooner than 4 days after finishing their last cycle of chemotherapy, and patients received no or limited lymphodepleting chemotherapy (12.5 mg/kg cyclophosphamide) 4 days before CAR$\mathrm{T}$ therapy. Otherwise, no chemotherapy was given to patients before or after $\kappa$.CAR infusion. Three dose levels of $\kappa$. CARs were administered: $2 \times 10^{7}, 1 \times 10^{8}$, and $2 \times 10^{8}$ cells $/ \mathrm{m}^{2}$. Among 4 patients with DLBCL treated with $\kappa$.CARs, 2 developed $\mathrm{CR}$ and 2 had no response. ${ }^{49}$

\section{CAR-Ts After HSCT for the Treatment of B-NHL}

The use of CAR-Ts after autologous HSCT (autoHSCT) in the NHL setting was also conducted in 2 phase I dose escalation clinical trials. Investigators at Memorial Sloan Kettering Cancer Center used an anti-CD19 (SJ25c) 1928z CAR-T for the treatment of tFL, DLBCL, transformed SMZL, and Burkitt lymphoma. ${ }^{50}$ Patients underwent BEAM (carmustine, etoposide, cytarabine, melphalan) conditioning before autoHSCT, and CAR-Ts were administered on days +2 and $+3 ; 7$ patients were treated at dose level of $5 \times 10^{6} 1928 \mathrm{zAR}-\mathrm{Ts} / \mathrm{kg}$, with 1 dose-limiting toxicity reported involving prolonged grade III/IV cytopenia and 1 non-relapse mortality due to mucormycosis pneumonia. One patient treated at a dose level of $1 \times 10^{7} \mathrm{CAR}-\mathrm{Ts} / \mathrm{kg}$ experienced a dose-limiting toxicity related to severe cytokine-release syndrome (sCRS) and fully recovered. All patients achieved neutrophil engraftment post-autoHSCT. Results showed that 5 of the 8 patients achieved CR (between 10 and 18 months of follow-up), 2 patients had disease progression, and there was 1 case of non-relapse mortality. ${ }^{50}$

Another study from City of Hope investigated the combination of anti-CD19 CAR-Ts and autologous bone marrow transplant for the treatment of NHL and took a slightly different approach by using a subpopulation of central memory $T$ cells $\left(\mathrm{T}_{\mathrm{CM}}\right)$ CAR-Ts. ${ }^{51}$ Previous preclinical studies have demonstrated the enhanced capacity of $\mathrm{T}_{\mathrm{CM}}$ cells to persist after adoptive transfer and to repopulate functional memory niches, as well as their self-renewal capacity and multipotency. ${ }^{52-54}$ The City of Hope trial used either the first-generation $19 z$ (cohort 1 ) or secondgeneration 1928z (cohort 2) CAR-Ts for the treatment of DLBCL or MCL. The HSCT conditioning regimen was not specified; however, all patients received bis-chloroethylnitrosourea, etoposide, cytarabine, and melphalan, and CD19 CAR-Ts were infused 2 to 3 days after stem cell infusion. ${ }^{51}$ The CAR-T dose ranged from $25 \times 10^{6}$ to $100 \times 10^{6} \mathrm{CAR} /$ injection (cohort 1 ) and $50 \times 10^{6}$ to $200 \times 10^{6} \mathrm{CAR} /$ injection (cohort 2). In cohort 1, 4 of 8 patients were progression-free at both 1 and 2 years; and in cohort 2, 6 of 8 patients were progression free at 1 year. The $\mathrm{T}_{\mathrm{CM}}$-derived anti-CD19 1928z CAR-Ts exhibited improvement in expansion; however, persistence was around 28 days, similar to that seen by others using other anti-CD19 second-generation CAR-Ts. 


\section{CAR-Ts Against HL and T-Cell Lymphomas}

Despite the relatively high rates of success with the current therapies against HL, $10 \%$ to $15 \%$ of patients with localized disease and $20 \%$ to $40 \%$ of those with advanced-stage disease will experience relapse, ${ }^{55,56}$ and an additional $10 \%$ to $15 \%$ are refractory to first-line therapy. ${ }^{57}$ Thus, alternative therapeutic strategies are required to treat patients with resistant/relapsed disease, and to reduce the morbidity attributable to chemotherapy/radiotherapy. HL tumor cells have a very low expression of CD19 antigen and therefore are not eligible for anti-CD19 therapy with CAR-Ts. ${ }^{23}$ However, despite the lack of CD19 expression, almost all HRS cells overexpress the CD123 and CD30 surface molecules, which could potentially be used as a target for adoptive Tcell therapy. ${ }^{24}$

Finding an ideal target in the T-cell lymphoma setting poses a much more challenging task due to shared expression of most targetable surface antigens between normal and malignant $T$ cells, potentially leading to fratricide of CAR-Ts or profound T cellrelated immunodeficiency. Therefore, options for targeted therapy of $\mathrm{T}$-cell malignancies remain scarce. In the preclinical setting, CD5-targeted CAR-Ts have been shown to be capable of specifically recognizing and killing malignant T-cell lines and primary T-cell ALL (T-ALL) blasts. Although expansion of CD5 CAR-Ts was preceded by transient fratricide, the extent of self-killing was limited. Interestingly, anti-CD5 CAR-Ts were capable of expanding in vitro, eradicating CD5+ malignant $\mathrm{T}$ cells and efficiently enhancing survival in xenograft mouse models. ${ }^{22}$ More recently, a novel anti-CD7 CAR-T was developed; CD7 is a transmembrane protein highly expressed in T-ALL and in a subset of peripheral T-cell lymphomas. Normal expression of CD7 is largely confined to $\mathrm{T}$ and $\mathrm{NK}$ cells, reducing the risk of off-target-organ toxicity. However, CAR-Ts were shown to display high expression of CD7 on their surface that led to massive fratricide. To overcome this limitation, CD7-targeted CAR-Ts modified with genomic editing to disrupt CD7 expression (CD7KO anti-CD7 CAR-T) demonstrated robust expansion and antitumor effect in the preclinical setting, with minimal fratricide. ${ }^{58}$

Preclinical studies have validated the potential benefits of using anti-CD30 or anti-CD123 CARTs for the treatment of HL. ${ }^{59,60}$ Recently, a clini- cal trial using a CD30-targeted second-generation CAR-T (CD30-CAR-T) was conducted in patients with $\mathrm{R} / \mathrm{R}$ EBV-negative, $\mathrm{CD} 30+\mathrm{HL}$ or $\mathrm{T}$ cell NHL (ie, anaplastic large cell lymphoma). ${ }^{61}$ In this trial, 9 patients (HL, $n=7$; NHL, $n=2$ ) received CD30-CAR-Ts; 2 were treated on dose level 1 $\left(2 \times 10^{7} \mathrm{CD} 30-\mathrm{CAR}-\mathrm{Ts} / \mathrm{m}^{2}\right), 2$ patients on dose level $2\left(1 \times 10^{8}\right)$, and 5 patients on dose level $3\left(2 \times 10^{8}\right)$. None of the patients received any conditioning regimen before CAR-T infusion. At 6 weeks follow-up, 1 patient presented with a CR, 1 achieved a very good $\mathrm{PR}$, and 4 had SD, whereas 3 patients had disease progression. ${ }^{61}$

\section{Side Effects}

Toxicity rates have varied significantly across studies, likely reflecting the differences in various factors, such as type of $\mathrm{scFv}$, costimulatory molecule, vector, preconditioning regimen, disease burden, and CAR$\mathrm{T}$ dose. In addition, different groups use distinctive criteria to define sCRS, which makes the comparison confusing. Overall, the side effects encountered with CAR-T therapy for NHL are very similar to those encountered in the B-ALL setting. ${ }^{1,3,4}$ The most common CAR-T-related side effects observed in the above-mentioned clinical trials were hypotension, hypoxia, acute renal failure, and neurotoxicity (confusion, aphasia, seizure/seizure-like events) (Table 1).

\section{Conclusions}

In the past 10 years, the field of cancer immunotherapy has seen remarkable advances, and the significant benefits observed with the use of CAR-Ts has brought new hope for the treatment of diseases once considered incurable. The initial success using CD19-targeted CAR-Ts against B-ALL has not only paved the way for the use of this treatment in a much broader spectrum of malignancies, but has also provided vital evidence toward understanding the side effects associated with this novel therapy. In the past few years, a significant number of clinical trials have shown unprecedented success in the treatment of NHL using T cells, mostly with CD19 as a target. The comparison between different costimulatory domains (CD28 vs 4-1BB) remains unanswered. Based on the results presented herein, CAR-Ts using either CD28 or 4-1BB costimulatory 
Role of CAR T Cells in NHL

\begin{tabular}{|c|c|c|c|c|c|c|}
\hline Year & Population & $\begin{array}{l}\text { scFv/ } \\
\text { Costimultatory } \\
\text { Domain }\end{array}$ & Vector & $\begin{array}{l}\text { Preconditioning } \\
\text { Chemotherapy }\end{array}$ & CAR T Cell Dose & CRS/Neurotoxicity \\
\hline $2012^{29}$ & $\begin{array}{l}\text { Adults: } \\
\text { B-NHL or CLL: } \\
4 \text { CLL } \\
3 \text { FL } \\
1 \text { SMZL }\end{array}$ & FMC63/CD28 & RV & $\begin{array}{l}\text { Flu: } 25 \mathrm{mg} / \mathrm{m}^{2} \times 5 \\
\text { Cy: } 60 \mathrm{mg} \times 2\end{array}$ & $3 \times 10^{6}$ to $3 \times 10^{7} / \mathrm{kg}$ & $\begin{array}{l}\mathrm{Gr}>3 \text { hypotension: } \mathrm{n}=2 \\
\mathrm{Gr}>3 \text { hypoxemia: } \mathrm{n}=2 \\
\mathrm{Gr}>3 \text { acute renal failure: } \\
\mathrm{n}=3\end{array}$ \\
\hline $2016^{35}$ & $\begin{array}{l}\text { B-NHL }(n=27): \\
13 \mathrm{DLBCL} \\
14 \mathrm{FL}\end{array}$ & FMC63/4-1BB & LV & $\begin{array}{l}\text { Investigator's } \\
\text { choice }\end{array}$ & $\begin{array}{l}\frac{\text { DLBCL }}{3.1 \times 10^{6}} \text { to } 6.75 \times 10^{6} / \mathrm{kg} \\
\frac{\mathrm{FL}}{3 \times 10^{6} \text { to } 8.8 \times 10^{6} / \mathrm{kg}}\end{array}$ & $\begin{array}{l}\text { DLBCL } \\
\text { Gr }>3 \text { CRS: } n=1 \\
\text { Gr }>3 \text { neurotoxicity: } n=1 \\
\frac{F L}{G r}>3 \text { CRS: } n=2 \\
\text { Gr } 5 \text { encephalitis: } n=1\end{array}$ \\
\hline $2017^{36}$ & $\begin{array}{l}\text { Adults: } \\
\text { B-NHL }(n=111) \text { : } \\
\text { DLBCL } \\
\text { PMBCL } \\
\text { FL }\end{array}$ & FMC63/CD28 & RV & $\begin{array}{l}\text { Flu: } 30 \mathrm{mg} / \mathrm{m}^{2} \times 3 \\
\text { Cy: } 500 \mathrm{mg} / \mathrm{m}^{2} \times 3\end{array}$ & $2 \times 10^{6} / \mathrm{kg}$ & $\begin{array}{l}\text { Gr }>3 \text { encephalopathy: } 24 \% \\
\text { Gr }>3 \text { CRS: } 20 \% \\
\text { Gr }>3 \text { neurotoxicity: } 29 \% \\
\text { Gr } 5 \text { hemophagocytic } \\
\text { lymphohistiocytosis: } n=1\end{array}$ \\
\hline $2016^{32}$ & $\begin{array}{l}\text { B-NHL: } \\
6 \text { DLBCL }\end{array}$ & FMC63/CD28 & RV & $\begin{array}{l}\text { Flu: } 30 \mathrm{mg} / \mathrm{m}^{2} \times 3 \\
\text { Cy: } 500 \mathrm{mg} / \mathrm{m}^{2} \times 3\end{array}$ & 1 to $20 \times 10^{6} / \mathrm{m}^{2}$ & Gr 2 CRS: $n=2$ \\
\hline $2016^{33}$ & $\begin{array}{l}\text { B-NHL }(n=32): \\
21 \mathrm{DLBCL} \\
5 \mathrm{FL} \\
4 \mathrm{MCL}\end{array}$ & FMC63/4-1BB & LV & $\begin{array}{l}\text { Cy: } 2-4 \mathrm{~g} / \mathrm{m}^{2}(\mathrm{~d} 1) \\
\text { Cy/Eto: Cy, 2-4 } \mathrm{g} / \mathrm{m}^{2}(\mathrm{~d} 1) \text { and } \\
\text { Eto, } 100-200 \mathrm{mg} / \mathrm{m}^{2}(\mathrm{~d} 1-3) \\
\text { Cy/Flu: Cy, } 60 \mathrm{mg} / \mathrm{kg} \text { (d1) and } \\
\text { Flu, } 25 \mathrm{mg} / \mathrm{m}^{2} \text { per either d2-4 } \\
\text { or d2-6 }\end{array}$ & $\begin{array}{l}2 \times 10^{5} \text { to } 2 \times 10^{7} / \mathrm{kg} \\
\text { (defined } 1: 1 \mathrm{CD} 4+/ \\
\text { CD8+ ratio) }\end{array}$ & $\begin{array}{l}\text { sCRS: } 4 / 32 \\
\text { Gr }>3 \text { neurotoxicity: } 9 / 32\end{array}$ \\
\hline $2017^{37}$ & $\begin{array}{l}\text { B-NHL }(n=51) \text { : } \\
\text { DLBCL }\end{array}$ & FMC63/4-1BB & LV & Not available & $\begin{array}{l}0.1 \text { to } 6.0 \times 10^{8} \text { cells/ } \\
\text { infusion }\end{array}$ & $\begin{array}{l}\text { Any gr CRS: } 57 \% \\
\text { Gr } 3 / 4 \text { CRS: } 26 \% \\
\text { Gr } 3 / 4 \text { neurotoxicity: } 13 \%\end{array}$ \\
\hline
\end{tabular}

Abbreviations: B-NHL, B-cell non-Hodgkin's lymphoma; CAR, chimeric antigen receptor; CLL, chronic lymphocytic leukemia; CRS, cytokine-release syndrome; Cy, cyclophosphamide; DLBCL, diffuse large B-cell lymphoma; Eto, etoposide; FL, follicular lymphoma; Flu, fludarabine; Gr, grade; LV, lentivirus; MCL, mantle cell lymphoma; PMBCL, primary mediastinal B-cell lymphoma; RV, retrovirus; scFv, single-chain variable fragment; sCRS, severe CRS (requiring intensive care unit management and treatment with tocilizumab and/or corticosteroids); SMZL, splenic marginal zone lymphoma.

domains have demonstrated similar clinical benefits and side effect patterns, and therefore which of the costimulatory domains is safer or displays better clinical outcomes is unknown. Another conclusion that can be drawn from the NHL trials is the absolute need for preconditioning chemotherapy, especially combination cyclophosphamide and fludarabine, to enable optimal function of the CAR-Ts - confirming what was previously observed in B-ALL trials. However, the outcomes and side effects observed with the 1:1 CD4+/CD8+ ratio of infused CAR-Ts was similar to those observed with unselected products. More results are needed before any conclusion can be drawn.
The clinical results observed with the use of CAR-Ts represent the beginning of this exciting and extremely promising new technology. New generations of CAR-Ts currently under development have demonstrated exciting preclinical results. ${ }^{11,62}$ Further, the combination of CAR-Ts and other drugs, such as checkpoint blockade inhibitors, could potentially significantly enhance the CAR-T antitumor therapeutic effect. ${ }^{63-65}$

In summary, adoptive T-cell therapy holds great potential to revolutionize cancer treatment, and with the advent of next-generation CAR-Ts, this therapy will likely be applied to a much broader spectrum of hematologic and solid malignancies.

\section{References}

1. Brentjens RJ, Davila ML, Riviere I, et al. CD19-targeted T cells rapidly induce molecular remissions in adults with chemotherapy-refractory acute lymphoblastic leukemia. Sci Transl Med 2013;5:177ra138.

2. Lee DW, Kochenderfer JN, Stetler-Stevenson M, et al. T cells expressing CD19 chimeric antigen receptors for acute lymphoblastic leukaemia in children and young adults: a phase 1 dose-escalation trial. Lancet 2015;385:517-528.

3. Maude SL, Frey N, Shaw PA, et al. Chimeric antigen receptor $\mathrm{T}$ cells for sustained remissions in leukemia. N Engl J Med 2014;371:1507-1517.

4. Davila ML, Riviere I, Wang $X$, et al. Efficacy and toxicity management of 19-28z CAR T cell therapy in B cell acute lymphoblastic leukemia. Sci Transl Med 2014;6:224ra225. 
5. Swerdlow SH, Campo E, Pileri SA, et al. The 2016 revision of the World Health Organization classification of lymphoid neoplasms. Blood 2016;127:2375-2390.

6. Weinstock DM, Dalla-Favera R, Gascoyne RD, et al. A roadmap for discovery and translation in lymphoma. Blood 2015;125:2175-2177.

7. Kuppers R, Engert A, Hansmann ML. Hodgkin lymphoma. J Clin Invest 2012;122:3439-3447.

8. Intlekofer AM, Younes A. Precision therapy for lymphoma—current state and future directions. Nat Rev Clin Oncol 2014;11:585-596.

9. Dann EJ, Daugherty CK, Larson RA. Allogeneic bone marrow transplantation for relapsed and refractory Hodgkin's disease and nonHodgkin's lymphoma. Bone Marrow Transplant 1997;20:369-374.

10. Heslop HE, Slobod KS, Pule MA, et al. Long-term outcome of EBV-specific T-cell infusions to prevent or treat EBV-related lymphoproliferative disease in transplant recipients. Blood 2010;115:925-935.

11. Zhao Z, Condomines M, van der Stegen SJ, et al. Structural design of engineered costimulation determines tumor rejection kinetics and persistence of CAR T cells. Cancer Cell 2015;28:415-428.

12. Srivastava S, Riddell SR. Engineering CAR-T cells: design concepts. Trends Immunol 2015;36:494-502.

13. Johnson LA, June $\mathrm{CH}$. Driving gene-engineered $\mathrm{T}$ cell immunotherapy of cancer. Cell Res 2107;27:38-58.

14. Abramson JS, Feldman T, Kroll-Desrosiers AR, et al. Peripheral T-cell lymphomas in a large US multicenter cohort: prognostication in the modern era including impact of frontline therapy. Ann Oncol 2014;25:2211-2217.

15. Vose J, Armitage J, Weisenburger D; on behalf of the International T-Cell Lymphoma Project. International peripheral T-cell and natural killer/Tcell lymphoma study: pathology findings and clinical outcomes. J Clin Oncol 2008;26:4124-4130.

16. Kehrl JH, Riva A, Wilson GL, Thevenin C. Molecular mechanisms regulating CD19, CD20 and CD22 gene expression. Immunol Today 1994;15:432-436.

17. Raponi S, De Propris MS, Intoppa S, et al. Flow cytometric study of potential target antigens (CD19, CD20, CD22, CD33) for antibody-based immunotherapy in acute lymphoblastic leukemia: analysis of 552 cases. Leuk Lymphoma 2011;52:1098-1107.

18. Dijoseph JF, Dougher MM, Armellino DC, et al. Therapeutic potential of CD22-specific antibody-targeted chemotherapy using inotuzumab ozogamicin (CMC-544) for the treatment of acute lymphoblastic leukemia. Leukemia 2007;21:2240-2245.

19. Horton HM, Bernett MJ, Pong E, et al. Potent in vitro and in vivo activity of an Fc-engineered anti-CD19 monoclonal antibody against lymphoma and leukemia. Cancer Res 2008;68:8049-8057.

20. Hekman A, Honselaar A, Vuist WM, et al. Initial experience with treatment of human B cell lymphoma with anti-CD19 monoclonal antibody. Cancer Immunol Immunother 1991;32:364-372.

21. McLaughlin P, Grillo-Lopez AJ, Link BK, et al. Rituximab chimeric antiCD20 monoclonal antibody therapy for relapsed indolent lymphoma: half of patients respond to a four-dose treatment program. J Clin Oncol 1998;16:2825-2833

22. Mamonkin M, Rouce RH, Tashiro H, Brenner MK. A T-cell-directed chimeric antigen receptor for the selective treatment of $\mathrm{T}$-cell malignancies. Blood 2015;126:983-992.

23. Herbst H, Tippelmann G, Anagnostopoulos I, et al. Immunoglobulin and T-cell receptor gene rearrangements in Hodgkin's disease and $\mathrm{Ki}$-1-positive anaplastic large cell lymphoma: dissociation between phenotype and genotype. Leuk Res 1989;13:103-116.

24. Pizzolo G, Romagnani S. CD30 molecule ( $\mathrm{Ki}-1 \mathrm{Ag}$ ): more than just a marker of CD30+ lymphoma. Haematologica 1995;80:357-366.

25. van der Stegen SJ, Hamieh M, Sadelain M. The pharmacology of secondgeneration chimeric antigen receptors. Nat Rev Drug Discov 2015;14:499_ 509.

26. Jensen MC, Popplewell L, Cooper LJ, et al. Antitransgene rejection responses contribute to attenuated persistence of adoptively transferred CD20/CD19-specific chimeric antigen receptor redirected $\mathrm{T}$ cells in humans. Biol Blood Marrow Transplant 2010;16:1245-1256.

27. Brentjens RJ, Santos E, Nikhamin Y, et al. Genetically targeted T cells eradicate systemic acute lymphoblastic leukemia xenografts. Clin Cancer Res 2007;13:5426-5435.

28. Kochenderfer JN, Wilson WH, Janik JE, et al. Eradication of B-lineage cells and regression of lymphoma in a patient treated with autologous $\mathrm{T}$ cells genetically engineered to recognize CD19. Blood 2010;116:4099_ 4102 .
29. Kochenderfer JN, Dudley ME, Feldman SA, et al. B-cell depletion and remissions of malignancy along with cytokine-associated toxicity in a clinical trial of anti-CD19 chimeric-antigen-receptor-transduced T cells. Blood 2012;119:2709-2720.

30. Kochenderfer JN, Dudley ME, Kassim SH, et al. Chemotherapy-refractory diffuse large B-cell lymphoma and indolent B-cell malignancies can be effectively treated with autologous $\mathrm{T}$ cells expressing an anti-CD19 chimeric antigen receptor. J Clin Oncol 2015;33:540-549.

31. Kochenderfer JN, Somerville RP, Lu T, et al. Long-duration complete remissions of diffuse large B cell lymphoma after anti-CD19 chimeric antigen receptor T cell therapy. Mol Ther 2017;25:2245-2253.

32. da Silva DG, Mukherjee M, Srinivasan M, et al. Direct comparison of in vivo fate of second and third-generation CD19-specific chimeric antigen receptor (CAR)-T cells in patients with B-cell lymphoma: reversal of toxicity from tonic signaling [abstract]. Blood 2016;128:Abstract 1851.

33. Turtle CJ, Hanafi LA, Berger C, et al. Immunotherapy of non-Hodgkin's lymphoma with a defined ratio of CD8+ and CD4+ CD19-specific chimeric antigen receptor-modified T cells. Sci Transl Med 2016;8:355ra116.

34. Brudno JN, Shi V, Stroncek D, et al. T cells expressing a novel fully human anti-CD19 chimeric antigen receptor induce remissions of advanced lymphoma in a first-in-humans clinical trial [abstract]. Blood 2016;128:Abstract 999.

35. Schuster SJ, Svoboda J, Nasta SD, et al. Treatment with chimeric antigen receptor modified T cells directed against CD19 (CTL019) results in durable remissions in patients with relapsed or refractory diffuse large B cell lymphomas of germinal center and non-germinal center origin, "double hit" diffuse large B cell lymphomas, and transformed follicular to diffuse large B cell lymphomas [abstract]. Blood 2016;128:Abstract 3026

36. Locke FL, Neelapu SS, Bartlett NL, et al. Clinical and biologic covariates of outcomes in ZUMA-1: a pivotal trial of axicabtagene ciloleucel (axi-cel; KTE-C19) in patients with refractory aggressive non-Hodgkin lymphoma (r-NHL) [abstract]. J Clin Oncol 2017;35(Suppl):Abstract 7512.

37. Novartis interim results from global, pivotal CTL019 trial show durable complete responses in adults with $\mathrm{r} / \mathrm{r}$ DLBCL. Available at: https://www. novartis.com/news/media-releases/novartis-interim-results-global-pivotalctl019-trial-show-durable-complete. Accessed October 10, 2017.

38. Abramson JS, Palomba L, Gordon L, et al. Transcend NHL 001 immunotherapy with the CD19-directed CAR T-cell product JCAR017 results in high complete response rates in relapsed or refractory B-cell nonhodgkin lymphoma [abstract]. Blood 2016;128:Abstract 4192.

39. Crump M, Neelapu SS, Farooq U, et al. Outcomes in refractory diffuse large B-cell lymphoma: results from the international SCHOLAR-1 study [published online ahead of print August 3, 2017]. Blood, doi: 10.1182/ blood-2017-03-769620.

40. Sotillo E, Barrett DM, Black KL, et al. Convergence of acquired mutations and alternative splicing of CD19 enables resistance to CART-19 immunotherapy. Cancer Discov 2015;5:1282-1295.

41. Yang W, Agrawal N, Patel J, et al. Diminished expression of CD19 in B-cell lymphomas. Cytometry B Clin Cytom 2005;63:28-35.

42. Gardner R, Wu D, Cherian S, et al. Acquisition of a CD19-negative myeloid phenotype allows immune escape of MLL-rearranged B-ALL from CD19 CAR-T-cell therapy. Blood 2016;127:2406-2410.

43. Gardner RA, Finney $\mathrm{O}$, Annesley $\mathrm{C}$, et al. Intent-to-treat leukemia remission by CD19 CAR T cells of defined formulation and dose in children and young adults. Blood 2017;129:3322-3331.

44. Budde LE, Berger C, Lin Y, et al. Combining a CD20 chimeric antigen receptor and an inducible caspase 9 suicide switch to improve the efficacy and safety of $\mathrm{T}$ cell adoptive immunotherapy for lymphoma. PLoS One 2013;8:e82742

45. Haso W, Lee DW, Shah NN, et al. Anti-CD22-chimeric antigen receptors targeting B-cell precursor acute lymphoblastic leukemia. Blood 2013;121:1165-1174

46. Wang Y, Zhang WY, Han QW, et al. Effective response and delayed toxicities of refractory advanced diffuse large B-cell lymphoma treated by CD20-directed chimeric antigen receptor-modified T cells. Clin Immunol 2014;155:160-175.

47. Zhang W, Wang Y, Guo Y, et al. Treatment of CD20-directed chimeric antigen receptor-modified $\mathrm{T}$ cells in patients with relapsed or refractory B-cell non-Hodgkin lymphoma: an early phase IIa trial report. Signal Transduct Target Ther 2016;1:16002

48. Till BG, Jensen MC, Wang J, et al. CD20-specific adoptive immunotherapy for lymphoma using a chimeric antigen receptor with both CD28 and 4-1BB domains: pilot clinical trial results. Blood 2012;119:3940-3950. 
49. Ramos CA, Savoldo B, Torrano V, et al. Clinical responses with $T$ lymphocytes targeting malignancy-associated $\mathrm{k}$ light chains. J Clin Invest 2016;126:2588-2596

50. Sauter CS, Riviere I, Bernal Y, et al. Phase I trial of $19-28 z$ chimeric antigen receptor modified T cells (19-28z CAR-T) post-high dose therapy and autologous stem cell transplant (HDT-ASCT) for relapsed and refractory (rel/ref) aggressive B-cell non-Hodgkin lymphoma (B-NHL) [abstract]. J Clin Oncol 2015;33(Suppl):Abstract 8515.

51. Wang X, Popplewell LL, Wagner JR, et al. Phase 1 studies of central memory-derived CD19 CAR T-cell therapy following autologous HSCT in patients with B-cell NHL. Blood 2016;127:2980-2990.

52. Berger C, Jensen MC, Lansdorp PM, et al. Adoptive transfer of effector CD8 $+\mathrm{T}$ cells derived from central memory cells establishes persistent T cell memory in primates. J Clin Invest 2008;118:294-305.

53. Wang $X$, Berger $C$, Wong $C W$, et al. Engraftment of human central memory-derived effector CD8+ T cells in immunodeficient mice. Blood 2011;117:1888-1898.

54. Graef $P$, Buchholz VR, Stemberger C, et al. Serial transfer of single-cellderived immunocompetence reveals stemness of CD8(+) central memory T cells. Immunity 2014;41:116-126.

55. Josting A, Franklin J, May M, et al. New prognostic score based on treatment outcome of patients with relapsed Hodgkin's lymphoma registered in the database of the German Hodgkin's lymphoma study group. J Clin Oncol 2002;20:221-230.

56. Yung L, Linch D. Hodgkin's lymphoma. Lancet 2003;361:943-951.

57. Santoro A, Bonadonna G, Valagussa P, et al. Long-term results of combined chemotherapy-radiotherapy approach in Hodgkin's disease: superiority of
ABVD plus radiotherapy versus MOPP plus radiotherapy. J Clin Oncol 1987;5:27-37.

58. Gomes-Silva D, Srinivasan M, Sharma S, et al. CD7-edited T cells expressing a CD7-specific CAR for the therapy of T-cell malignancies. Blood 2017;130:285-296.

59. Ruella M, Klichinksy M, Kenderian SS, et al. Overcoming the immunosuppressive tumor microenvironment of hodgkin lymphoma using chimeric antigen receptor T cells. Cancer Discov 2017;7:1154-1167.

60. Savoldo B, Rooney CM, Di Stasi A, et al. Epstein Barr virus specific cytotoxic $\mathrm{T}$ lymphocytes expressing the anti-CD30zeta artificial chimeric T-cell receptor for immunotherapy of Hodgkin disease. Blood 2007;110:2620-2630.

61. Ramos CA, Ballard B, Liu E, et al. Chimeric T cells for therapy of CD30+ Hodgkin and non-Hodgkin lymphomas [abstract]. Blood 2015;126:Abstract 185 .

62. Pegram HJ, Lee JC, Hayman EG, et al. Tumor-targeted T cells modified to secrete IL-12 eradicate systemic tumors without need for prior conditioning. Blood 2012;119:4133-4141.

63. John LB, Devaud C, Duong CP, et al. Anti-PD-1 antibody therapy potently enhances the eradication of established tumors by gene-modified T cells. Clin Cancer Res 2013;19:5636-5646.

64. John LB, Kershaw MH, Darcy PK. Blockade of PD-1 immunosuppression boosts CAR T-cell therapy. Oncoimmunology 2013;2:e26286.

65. Avanzi MP, van Leeuwen DG, Li X, et al. IL-18 secreting CAR T cells enhance cell persistence, induce prolonged $\mathrm{B}$ cell aplasia and eradicate CD19+ tumor cells without need for prior conditioning [abstract]. Blood 2016;128:Abstract 816 